\title{
Adquisición de las consonantes vibrantes en español de Chile en una muestra de informantes entre $2 ; 0$ y 3;11 años ${ }^{1}$
}

\section{Rhotic consonant acquisition in Chilean Spanish in a sample of subjects between 2;0 and 3;11 years}

\author{
PILAR VIVAR VIVAR \\ LESLIE FIGUEROA ALARCÓN
}

\author{
Universidad Católica de Temuco. \\ Correo electrónico: pvivar@uct.cl \\ Universidad Católica de Temuco. \\ Correo electrónico: prof.lesliefigueroa@gmail.com
}

\begin{abstract}
Se investigó la adquisición de las consonantes vibrantes en español de Chile en una muestra compuesta por 161 informantes, divididos en cuatro grupos etarios desde los 2;0 hasta los 3;11 años de edad. Se analizaron los resultados en función de las variables edad y nivel socioeconómico (NSE). Para obtener los datos se utilizó la prueba CEFI: "Cuestionario para la Evaluación de la Fonología Infantil”. La producción de las vibrantes fue analizada como normal, sustituida y omitida. Se observó que el rendimiento general de las vibrantes evidenció un aumento en el porcentaje de emisión normal en relación con el avance en la edad de los sujetos, sin embargo, entre los 3;0 y 4;0 años la vibrante múltiple sólo alcanza un $24 \%$ de producción normal, mientras que la simple, un $60 \%$. En cuanto al fenómeno de sustitución, las vibrantes múltiples fueron sustituidas con mayor frecuencia por las consonantes líquidas [l] y [r] y por las consonantes dentales [ð] y [d]; mientras que, las vibrantes simples; por las consonantes [l], [ð] y [n]. Finalmente, se concluye que en la muestra analizada no existen diferencias significativas según la variable NSE durante la producción de los fonemas vibrantes antes de los cuatro ańos de edad.
\end{abstract}

Palabras clave: adquisición fonológica, español de Chile, vibrante simple, vibrante múltiple.

The research has been conducted on the rhotic consonants in Chilean Spanish in a sample of 161 subjects, divided in four age groups between 2;0 and 3,11 years. The variables taken into account to analyse the results are age and NSE. To obtain the data, the CEFI ("Cuestionario para la Evaluación

\footnotetext{
${ }^{1}$ Esta investigación se ha desarrollado en el marco del proyecto Fondecyt de Iniciación N 11140414: "Desarrollo fonológico-fonético infantil en niños entre 2,0 y 3,11 años. Un estudio transversal - descriptivo con aplicación de la prueba articulatoria CEFI"
} 
de la Fonología Infantil") test was applied. The vibrant production was analysed as correct, substituted and omitted. The general observation of the rhotic outcome is that there is a higher degree of normal emission according to the subjects age. Nevertheless, between 3;0 and 4;0 years the trill reaches only a $24 \%$ of correct production, while in case of the flap it is a $60 \%$. In case of the substitution, the trills were substituted mostly by liquid consonants [l] and [r] and by dental consonants [ð] and [d]; while in case of the flaps it was mainly by the consonants l], [ð] and [n]. The conclusion is that in the sample we analysed there are no meaningful socio-economic differences in the production of rhotic phonemes before the age of four.

Key words: phonological acquisition, Chilean Spanish, flap, trill.

\section{INTRODUCCIÓN}

La adquisición fonológica es un proceso complejo que consiste en la paulatina dominación articulatoria de los sonidos y el manejo de las reglas fonotácticas de la lengua materna. En las investigaciones sobre este ámbito, el paradigma más utilizado ha sido el de naturaleza articulatoria, que analiza la incorporación de los fonemas y grupos fonemáticos en el repertorio fonológico del niño/a (Templin 1957, Bosch 2004, Vivar \& León 2009, Vivar 2009). Este enfoque, junto con el de la fonología natural (Stampe 1969), abarcan principalmente la descripción segmental. Específicamente, en el plano articulatorio, la mayoría de los estudios han establecido rangos etarios y sobre ellos se han constituido los segmentos que estarían adquiridos para tales edades. Lo anterior ha permitido establecer mediante frecuencias de aparición, el orden de dificultad en la producción de los segmentos. La importancia de este tipo de investigaciones es que permiten establecer un patrón de adquisición normal y de esta manera poder identificar a niños con retrasos o trastornos en el desarrollo de su sistema fonológico.

En general, existe coincidencia entre los autores en que a los 3 años las características básicas del sistema fonológico ya estarían presentes y la mayoría de los niños pueden producir los sonidos de casi todas las vocales y consonantes de su lengua materna (Berko \& Bernstein 2010, Lleó 1997, Bosch 2004, Ingram 1987, entre otros). Sin embargo, es probable que existan adquisiciones tardías en el plano consonántico, como por ejemplo la líquida vibrante /r/. Para el español de Chile, Vivar y León (2009) evidenciaron que los principales avances fonológicos se producen previo a los 3;0 años, sin embargo, sobre esa edad continúan persistiendo sustituciones y omisiones, mayoritariamente en las consonantes vibrantes. Tomando en cuenta los antecedentes anteriores, la siguiente investigación tuvo por objetivo conocer el desarrollo fonético-fonológico de las vibrantes múltiple y simple en una muestra de 161 informantes del espańol de Chile cuyas edades fluctúan entre los 2; 0 hasta los 3;11 ańos de edad divididos en cuatro grupos etarios.

Tradicionalmente, el sonido $[\mathrm{r}$ ] en español, ha sido caracterizado como vibrante, múltiple, alveolar, sonora, oral (Navarro Tomás 1918, Quilis \& Fernández 1971, Obediente 
2007, entre otros), sin embargo, su articulación netamente vibrante ha sido cuestionada debido a la variedad de alófonos que presenta entre las distintas zonas de Hispanoamérica. Específicamente, para el español de Chile, varios autores han identificado variación alofónica de este sonido (Borland 2004, Soto 2011, Sadowsky \& Salamanca 2011, Retamal \& Soto 2017). Por ejemplo, Soto (2011) identifica la presencia de 3 alófonos en posición inicial, intervocálica y precedida de nasal o lateral: vibrante múltiple [r], aproximadamente [I] y fricativa asibilada [I]. En esta línea, Garnica y Edward (1977) señalan que durante la adquisición fonológica existen sonidos estables, sonidos sustituibles estables y sonidos variables. Los dos primeros, podrían utilizarse para observar y evaluar la etapa de desarrollo fonológico, mientras que el tercer tipo podría utilizarse para observar los fenómenos de variación sociolingüística. En el sentido anterior, la siguiente investigación se enfoca en la adquisición fonológica de las vibrantes en cuanto a la descripción de las sustituciones fonológicas y omisiones de este sonido.

En el siguiente artículo se entrega información lingüística sobre la articulación de las vibrantes mediante el análisis de las frecuencias de aparición de las emisiones normales, ${ }^{2}$ sustituidas y omitidas. Además de la variable edad, se incluye el nivel socioeconómico con el propósito de evidenciar si esta variable influye significativamente en el porcentaje de producción normal de los segmentos analizados.

\section{Marco teórico}

\subsection{Adquisición de las consonantes vibrantes}

En el plano de la adquisición fonológica, varios estudios han demostrado que la adquisición tardía de las vibrantes frente a otras clases de sonidos se manifiesta de forma reiterada en varias lenguas, incluyendo el español. Así lo indican Anderson y Smith (1987):

Los análisis de substitución también arrojan evidencias de que existen patrones comunes de adquisición en otras lenguas. Por ejemplo, al igual que en los estudios de niños que aprenden inglés, árabe, alemán, ruso, italiano y japonés (referidos en Locke 1993), los niños de habla espańola del presente estudio mostraron mayores niveles de precisión en las categorías oclusiva, nasal y semivocal que en las fricativas, laterales y vibrantes, para todas las posiciones silábicas/codas silábicas/ estructura silábica. Se ha observado este mismo patrón en otros estudios con niños hispanohablantes. Por ejemplo, Macken (1975) y González (1981) señalan que, en los análisis que realizaron a niños de habla española, los sonidos laterales y vibrantes fueron también los menos precisos y se produjeron en una etapa posterior de su desarrollo (1987: 72, trad. mía).

\footnotetext{
${ }^{2}$ El término normal se utiliza para referirse al modelo fonológico adulto.
} 
Son variados los elementos que pueden estar involucrados la adquisición tardía de algunos segmentos: "si bien a priori parece aceptable el hecho de plantear la noción de dificultad para la correcta realización de determinados sonidos, sobre todo si tenemos en cuenta el movimiento articulatorio involucrado o la precisión y velocidad requeridas en el habla fluida (...)" (Bosch 2004:21). En relación con lo anterior, Dinnsen et al. (1990) plantean 5 niveles de complejidad, en el que en el último nivel aparecerían las distinciones de lateralidad para las líquidas que permite la vibrante. En cuanto al desarrollo motor, en la actualidad se considera que la articulación de sonidos cada vez más complejos, está relacionada con la maduración del control motor. Así, para la articulación de las consonantes vibrantes es requerida la curvatura de la lengua y para las fricativas, el perfeccionamiento en la regulación de la fricción según los lugares de articulación en que éstas se producen (Stokes \& Surendran 2005).

Tal como se ha señalado en las líneas anteriores, la adquisición tardía del sonido vibrante ha sido evidenciada en diversos estudios. Específicamente, para el inglés, Templin (1957) investigó a 480 niños entre 3,0 y 8,0 años de edad, resultados demuestran que las vibrantes se adquieren a los 4 años. Por su parte, Olmsted (1971) investigó la producción espontánea de los sonidos en 100 niños entre los 1;3 a 4;6 años de edad y sus resultados coinciden con los de Templin (1957) en relación con la edad de adquisición del segmento vibrante.

Para el español peninsular, Serra i Raventós (1984) investigó la articulación de consonantes aisladas y grupos consonánticos de 628 nińos barceloneses por medio de la repetición (imitación inmediata) de palabras presentadas en 34 imágenes. Los sujetos del estudio fueron divididos en 5 grupos etarios (3;0-3;11, 4;0-4;11, 5;0-5;11, 6;0-6;11, 7;0$7 ; 11)$. El porcentaje de error de las vibrantes fue de $35,6 \%$ en el primer grupo etario, mientras que, para el último, este porcentaje disminuyó a $11 \%$.

Por su parte, González Valenzuela (1989) analiza las producciones fonológicas de 198 sujetos malagueños entre 3;0 y 6;11 años (3;0-3;11 años, 4;0-4;11 años, 5;0-5;11 años, 6;0-6;11 años) a través de una prueba screening ( 40 palabras). Respecto a la adquisición de vibrantes, las conclusiones revelan que la sustitución fue el proceso más utilizado por los niños. En relación al nivel sociocultural, los resultados indican que no existen diferencias significativas en las emisiones normales de la vibrante simple. Por su parte Bosch (2004) analiza el desarrollo fonológico infantil por medio de las producciones espontáneas en 293 niños barceloneses entre 3;0 y 7;11 años de edad. Los resultados en torno a las vibrantes señalan que la vibrante simple a los 3;0 ańos es reemplazada por la aproximante [ð], mientras que la vibrante múltiple es sustituida por la vibrante simple $[\mathrm{r}]$ o la aproximante [ð]. A los 4;0 años, la vibrante simple ya se ha adquirido, mientras que, la vibrante múltiple se sustituye aún por los fonemas $/ \mathrm{r} /$ y / / /. En relación a los estudios en torno a la adquisición de las vibrantes en el español de América, Anderson y Smith (1987) investigaron la producción fonológica en 6 niños puertorriqueños de 2;0 años de edad mediante habla espontánea y concluyen que las vibrantes $[r]$ y $[r]$ fueron las consonantes que presentaron mayor dificultad para los niños. Las sustituciones más comunes para estos sonidos fueron: a) articulación de fricativa glotal por vibrante múltiple $(\mathrm{h} / \mathrm{r})$; b) sustitución de vibrantes por laterales $(1 / \mathrm{r}, 1 / \mathrm{r})$; $y, c)$ sustitución de vibrante simple por oclusiva glotal y por fricativa alveolar sorda $(R / \mathrm{r}, \mathrm{s} / \mathrm{r})$. 
Golstein y Cintrón (2000) analizaron los tipos de sílabas y longitud de palabras en tres niños puertorriqueños de 1;10,2;4 y 2;5 años de edad por medio del registro y análisis del habla espontánea. En relación con el fenómeno de omisión de las consonantes, los investigadores observaron que la vibrante simple / / / fue la consonante que más se omitió (28 veces- $85 \%$ ) en posición intermedia de palabra; mientras que, las consonantes que más se omiten después de la líquidas (vibrantes principalmente) son las oclusivas, las glotales y fricativas. En relación al fenómeno de sustitución, éste se produjo con mayor frecuencia en las consonantes líquidas, específicamente, las fricativas $[\beta]$ y $[ð]$ sustituyeron a la vibrante simple, mientras que $[\mathrm{l}]$ y [h] sustituyeron a la vibrante múltiple.

Camargo (2006) investigó el desarrollo fonético-fonológico en 472 infantes colombianos (Bogotá) entre 0;0 y 6;0 años mediante observaciones guiadas por cuestionarios. Sus resultados muestran que, los nińos entre los 2;0 y 3;0 ańos todavía no producen los fonemas vibrantes y éstos son sustituidos principalmente por el fonema /1/. Entre los 3;0 y 4;0 años "se evidenció una etapa de adquisición del fonema vibrante simple e inicios del vibrante múltiple" (Camargo 2006: 7).

Flores y Ramírez (2016) estudiaron el orden de adquisición de los fonemas consonánticos en dos sujetos mexicanos de 2 y 4 ańos, respectivamente, mediante el Cuestionario para la evaluación de la Fonología Infantil CEFI. En las producciones del niño de 2;0 años "la vibrante simple es omitida y sustituida por un alargamiento de vocal en posición de ataque y omitida completamente en posición final [...], la vibrante múltiple se sustituye por el fonema /1/ en posición de ataque y es omitida completamente al final de sílaba" (Flores y Ramírez 2016: 6). En las emisiones del niño de 4;0 años, por otro lado, "se observó que la vibrante simple es debilitada al inicio de palabra y sílaba [por el contrario] la vibrante múltiple es pronunciada con claridad al inicio de sílaba en medio de palabra" (Flores y Ramírez 2016: 5), pero al inicio de palabra se sustituye por la vibrante simple.

Igualmente, para el español de México, Oropeza (2017) estudió la adquisición de las líquidas en un grupo conformado por 55 nińos entre 2;0 y 6;0 ańos de edad mediante una tarea de nombrado. Se destaca que en posición inicial de palabra los menores suelen omitir las líquidas, aunque también sustituyen las vibrantes, por ejemplo, /r/ por /d/ / řeyálo/-[deyálo]. En posición intervocálica, las vibrantes $/ \mathrm{r} / \mathrm{y} / \mathrm{r} /$ se suelen sustituir por otros fonemas, principalmente por $/ \mathrm{d} / \mathrm{y} / ð /$. Por un lado, algunos ejemplos de sustitución de /s/ por /l/ son: /paxaríto/-[pakalito], /periko/-[pelíto]; de/f/ por/g/: /péra/-[péya] y de

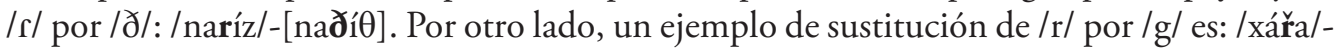
[áya] y de /r/ por /l/: /péřo/-[pélo]. Según Oropeza (2017) esto indicaría que los segmentos consonánticos intervocálicos se adquieren primero.

\subsection{Adquisición de las consonantes vibrantes en el Español de Chile}

Coloma et al. (2010) estudiaron el desarrollo fonológico de 180 niños santiaguinos entre 3;0 y 5;0 años distribuidos en dos grupos etarios (3;0-3;11 y 4;0-4;11), por medio del test para Evaluar Procesos de Simplificación Fonológica (TEPROSIF-R) basado en los 
preceptos teóricos de la fonología natural de Stampe (1969). Los autores exponen que los niños omiten elementos de las palabras, pero mantienen las unidades tónicas de ellas, porque "son las más perceptibles y estables" (Coloma et al. 2010: 42). En cuanto a las sustituciones, los menores mayoritariamente sustituyeron la /r/ por / $/ \mathrm{f}$ o /l/. En esta misma línea, Torres et al. (2016) investigaron la adquisición de los fonemas lateral y róticos en 84 niños santiaguinos entre $3 ; 0$ y $4 ; 11$ años de edad divididos en cuatro grupos $(3 ; 0-3 ; 5$, $3 ; 6-3 ; 11,4 ; 0-4 ; 5,4 ; 6-4 ; 11)$. Entre sus principales resultados, señalan que "a mayor edad, mayor es el porcentaje de aparición de los fonemas, con excepción del fonema vibrante múltiple /r/ para el rango etario de los 4;06 - 4;11, donde se observa una disminución en el porcentaje de producción" (Torres et al. 2016: 8), aun así, la producción de la vibrante múltiple es menor que la vibrante simple.

En Chile, los estudios sobre adquisición de los elementos fonológicos desde una perspectiva articulatoria son escasos. La primera descripción sobre la inserción de elementos fonológicos desde una perspectiva articulatoria fue realizada por Vivar y León (2009) quienes establecieron una cronología de secuencia de adquisición del repertorio fonéticofonológico en una muestra de 72 informantes de Concepción entre los 3;0 hasta 5;11 años de edad mediante el Cuestionario para la Evaluación de la Fonología Infantil CEFI. El cuestionario para la Evaluación Infantil consta de 49 láminas (imágenes) en las que se evalúan los fonemas oclusivos, fricativos, africados y sonantes en posición inicial, media y final. Además, la prueba organiza los fonemas consonánticos en consonantes aisladas, grupos consonánticos y diptongos. En términos generales, se evidenció que en pocos años $(3 ; 0)$ se produce una adquisición rápida de fonemas $(80 \%)$ para luego lentificarse en los siguientes tres años.

Según Vivar y León (2009), las nasales fueron las consonantes que tuvieron mayor porcentaje de emisión normal, por el contrario, las sordas continuas y las líquidas fueron las de mayor dificultad durante su producción. Dentro del grupo de las líquidas, las vibrantes (vibrante múltiple) fue la consonante que presentó mayor dificultad articulatoria. Específicamente, la vibrante simple se sustituyó por los fonemas $/ \mathrm{j} /$, /l/, /d/, /f/ y /n/, aunque fue más frecuente por $/ \mathrm{j} /$, /l/. Por su parte, la vibrante múltiple fue reemplazada, de este modo, por $/ \mathrm{l} /, / \mathrm{x} / \mathrm{y} / \mathrm{t} /$, aunque particularmente por $/ \mathrm{d} /, / \mathrm{f} / \mathrm{y} / \mathrm{j} /$. Los porcentajes de articulación alcanzado según rango etario para cada vibrante se presentan en el Cuadro 1: 
Cuadro 1. Ajuste porcentual de adquisición de las vibrantes por edad (Vivar 2007: 56)

\begin{tabular}{|c|c|c|c|c|c|c|}
\hline $\begin{array}{c}\text { Ajuste } \\
\text { porcentual }\end{array}$ & $\begin{array}{c}\text { I grupo } \\
3,0-3,5 \\
\text { años }\end{array}$ & $\begin{array}{c}\text { II grupo } \\
3,6-3,11 \\
\text { años }\end{array}$ & $\begin{array}{c}\text { III grupo } \\
4,0-4,5 \\
\text { años }\end{array}$ & $\begin{array}{l}\text { IV grupo } \\
4,6-4,11 \\
\text { años }\end{array}$ & $\begin{array}{c}\text { V grupo } \\
5,0-5,5 \\
\text { años }\end{array}$ & $\begin{array}{c}\text { VI grupo } \\
5,6-5,11 \\
\text { años }\end{array}$ \\
\hline $100 \%$ & & & & & /f/ & /fl \\
\hline $90 \%$ & & & $\mid \mathrm{f} /$ & $\mid \mathrm{f} /$ & & \\
\hline $80 \%$ & & /f/ & & & & $\mid \mathbf{r} /$ \\
\hline $70 \%$ & $\mid \mathrm{f} /$ & $|\mathbf{r}|$ & $|\mathbf{r}|$ & $|\mathbf{r}|$ & $|\mathbf{r}|$ & \\
\hline $60 \%$ & & & & & & \\
\hline $50 \%$ & & & & & & \\
\hline $40 \%$ & & & & & & \\
\hline $30 \%$ & $|\mathbf{r}|$ & & & & & \\
\hline
\end{tabular}

Se concluye que los fonemas vibrantes tienen bajos porcentajes de emisión normal en comparación con otros fonemas de la lengua (Bosch 2004 y Vivar 2007), sin embargo, las producciones normales aumentan a medida que el niño crece (González 1989, Bosch 2004; Serra i Raventós 1984; Torres et al. 2016 y Vivar y León 2009). La causa de lo anterior radica en que la vibrante múltiple es una las consonantes líquidas que se adquiere tardíamente, alrededor de los 6;0 años según Bosch (2004) y más tarde aún, según Vivar (2007). La vibrante simple, por el contrario, se adquiere a los 4;0 años (Bosch 2004 y Camargo 2006) o a los 5;0 años (Vivar 2007 y Torres et al. 2016).

A pesar de no lograr producir normalmente estos fonemas vibrantes, los niños buscan soluciones parciales para conseguir emitirlos, denominados procesos no normales o de simplificación, tales como: sustitución, omisión y modificación (Bosch 2004, Camargo 2006, Coloma et al. 2010, Flores y Ramírez 2016, Goldstein y Cintrón 2000, González 1989, Merlo et al. 2004, Oropeza 2017 y Vivar y León 2009).

Respecto a los procesos de simplificación, desde la perspectiva de González (1989), estos tienen relación, a veces, con variables dialectales. Además, entre los procesos no normales, el que emplean constantemente los niños es la sustitución. Los autores evidencian que la vibrante simple se sustituye por /ð/ (Bosch 2004; Goldstein y Cintrón 2000 y Oropeza 2017), /d/ (Oropeza 2017 y Vivar y León 2009), /l/ (Camargo 2006 y Vivar y León 2009), / $/$ / (Goldstein y Cintrón 2000), /n/, /f/ y /j/ (Vivar y León 2009). Por otra parte, la vibrante múltiple se sustituye por /r/ (Bosch 2004; , Coloma et al. 2010; Flores y Ramírez 2016 y Vivar y León 2009), /1/ (Camargo 2006; Coloma et al. 2010; Flores y Ramírez 2016; Goldstein y Cintrón 2000 y Vivar y León 2009), /ð/ (Bosch 2004 y Oropeza 2017), /d/ (Oropeza 2017 y Vivar y León 2009), /h/ (Goldstein y Cintrón 2000), /t/, /. / y /j/ (Vivar y León 2009). 


\section{Metodología}

\subsection{Diseño de la investigación y participantes}

Se abordó un diseño metodológico mixto, cualitativo y cuantitativo, no experimental y de tipo transeccional descriptivo. Las unidades de observación en la investigación correspondieron a informantes entre 2;0 a 3;11 años. El acceso a los participantes se obtuvo partir del contacto previo con jardines infantiles y sólo luego de la obtención del consentimiento informado de padres y apoderados de los participantes.

Se procuró que los informantes no presentaran alteraciones fisiológicas en su aparato fonador que pudiesen influir en su desempeño en el instrumento que se les aplicó. Para dicho fin, se utilizó la información entregada por los jardines infantiles sobre alteraciones fisiológicas y retrasos en el lenguaje diagnosticados.

Los participantes fueron seleccionados en función de la edad, de la distribución geográfica (ciudad de procedencia) y el nivel socioeconómico. Las variables utilizadas para describir - y analizar - la cronología de secuencia de adquisición del repertorio fonéticofonológico fueron seleccionadas a partir de criterios teóricos y empíricos. La muestra se dividió en 4 grupos etarios: grupo etario I (2;0 a 2;5 años), grupo etario II (2;6 a 2;11 años), grupo etario III (3;0 a 3;5 años) y grupo etario IV (3;6 a 3;11 años). En definitiva, se entrevistaron a 192 informantes de los cuales se hicieron válidas para el análisis 161 encuestas. Según las variables estudiadas el número de informantes $\left(\mathrm{N}^{\circ}\right)$ analizados se detalla en el Cuadro 2:

Cuadro 2. Número de informantes según variables analizadas

\begin{tabular}{|c|c|l|c|l|l|}
\hline Grupo etario & $\mathbf{N}^{\circ}$ & \multicolumn{1}{|c|}{ Ciudad } & $\mathbf{N}^{\circ}$ & \multicolumn{1}{|c|}{ NSE } & $\mathbf{N}^{\circ}$ \\
\hline I & 33 & Antofagasta & 38 & Alto & 43 \\
\hline II & 41 & Punta Arenas & 43 & Medio & 63 \\
\hline III & 44 & Santiago & 45 & Bajo & 55 \\
\hline IV & 43 & Temuco & 35 & & \\
\hline
\end{tabular}

\subsection{Tarea de elicitación}

Para la recolección de los datos se utilizó el test de origen mexicano: Cuestionario para la Evaluación de la Fonología Infantil (CEFI) (Ávila, 1990) la cual fue adaptada al español de Chile (Vivar, 2007; Vivar y León 2009).CEFI es una prueba de denominación en la cual se le presentan las láminas de manera individual al niño/a y se le pide nombrar lo que ve en ellas. La ventaja de las pruebas de dominación en fonología es que contienen 
imágenes seleccionadas en función de los elementos fonológicos target que se desean evaluar lo que permite un mayor control de las respuestas y un análisis comparativo homogéneo de los resultados.

La evaluación se aplicó de manera individual procurando un ambiente acústicamente adecuado y sin factores distractores. La prueba se presentó como un juego en el cual se les solicitó a los informantes que expresen verbalmente lo que veían en cada lámina. Sus respuestas fueron inducidas por las entrevistadoras con preguntas del tipo: ¿qué es eso? ¿qué hace? ¿de qué color es? Etc. En los casos en que el informante no logró identificar el concepto deseado se realizó una repetición diferida del mismo. El promedio de duración de la prueba fue de 15 minutos y cada entrevista fue grabada en un equipo TASCAM D-40. Esta herramienta consta de 49 láminas que en su mayoría representan sustantivos. Las láminas elicitan palabras que evalúan la producción de las consonantes aisladas, grupos consonánticos (ataques complejos, codas y grupos mixtos) y diptongos. Los fonemas consonánticos tienen la facultad de ser evaluados en más de una lámina y en todas sus posiciones posibles, respetando las restricciones fonotácticas de la lengua. En definitiva, CEFI provee 122 datos fonéticos obtenidos de 49 palabras. Para fines del siguiente estudio, se seleccionaron aquellas láminas en las que se evalúa a las vibrantes en posición intervocálica (Cuadro 3):

Cuadro 3. Palabras evaluadas

\begin{tabular}{|l|l|l|}
\hline Posición & /r/ & /r/ \\
\hline Inicial & & $\begin{array}{l}\text { reloj } \\
\text { ruedas } \\
\text { resbaló }\end{array}$ \\
\hline Media & amarillo & perro \\
& jirafa \\
& naranja & gorro \\
\hline
\end{tabular}

\subsection{Procesamiento de los datos y análisis estadísticos empleados}

Se obtuvo un archivo de audio por informante el cual fue identificado con una serie de números que daban cuenta de las variables a analizar. Posteriormente, las emisiones fueron almacenadas y transcritas fonéticamente (Alfabeto Fonético Internacional) en el programa PHON (https://www.phon.ca/phontrac). Posteriormente, los análisis fueron exportados a formato de archivo excel (xlsx), para su tratamiento directo con el software de Análisis Estadístico SPSS. Se utilizó este último para la cuantificación del número de emisiones correctas según distribución geográfica, grupo de edad y nivel socioeconómico. En primer lugar, a nivel univariado: porcentajes de emisiones normales para cada una de las categorías fonéticas en general, tramo de edad y nivel socioeconómico. Se utilizaron 
medidas porcentuales para describir los resultados obtenidos, como indicador de centralidad sobre las codas, consonantes o grupos consonánticos que presentaban mayor cantidad de veces de emisiones correctas. Por otro lado, se emplearon algunas técnicas inferenciales, particularmente el Anova de un factor, con el fin de observar si las diferencias observadas a pequeña escala podrían, potencialmente, generalizarse a la población con un diseño muestral probabilístico definido.

\section{Resultados}

\subsection{Emisión normal, sustitución y omisión/ resultados generales}

Se evaluó la articulación de cada fonema como: normal, ${ }^{3}$ sustituida y omitida. La consonante $/ \mathrm{r} /$ evidenció un $12,4 \%$ de producción normal frente a un $61 \%$ de sustituciones y un $12,0 \%$ de omisiones. Por su parte, la consonante /r/ presentó un 33,5\% de producción normal, un $42,4 \%$ de sustituciones y un $18,6 \%$ de omisiones. En definitiva y, tal como se observa en la Figura 1, los nińos de la muestra sustituyeron mayoritariamente ambos fonemas, seguido por la emisión normal de las vibrantes y, por último, la omisión de dichas consonantes. La consonante /r/ en contraste con / $/$ / fue sustituida más veces de acuerdo al número de veces que debió ser emitida normalmente. Por otro lado, la vibrante simple tiene un mayor porcentaje de emisión normal en comparación con la vibrante múltiple, al igual que el porcentaje de omisión.

Figura 1. Porcentaje (\%) de emisión normal, omisión y sustitución de los fonemas /r/ y /r/

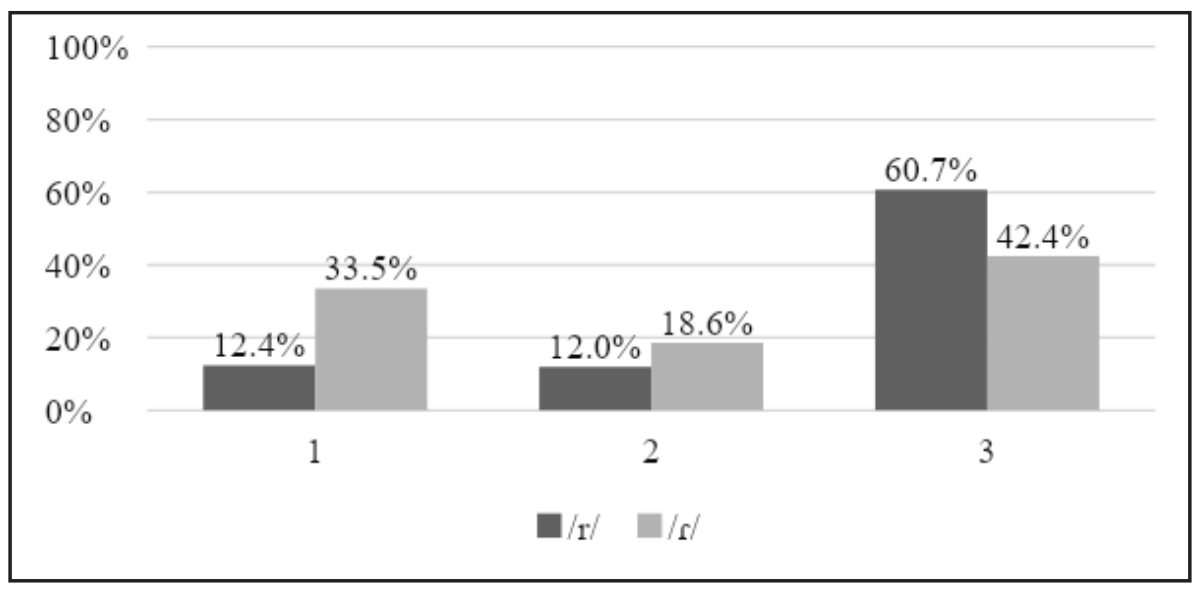

\footnotetext{
${ }^{3}$ Normal se refiere según modelo adulto.
} 
En relación al fenómeno de sustitución, la vibrante múltiple $/ \mathrm{r} /$ se sustituyó por los siguientes fonemas en posición aislada: /b/, /d]/, /g/, /g/, / / /, /il/, /j/, /m/, /n/, / / $/, / \mathrm{s} /, / \mathrm{t} /$, $|\mathrm{g} /, / \mathrm{x} /|, K /, / \beta /$ y $/ \theta /$. El porcentaje de sustitución de $/ \mathrm{r} /$ por las consonantes mencionadas no alcanza el $10 \%$, por ejemplo, la sustitución por el fonema /t/ se evidencia sólo en un $4 \%$; mientras que la sustitución por las consonantes $/ \mathrm{g} /, / \theta /, / \mathrm{i} /, / \mathrm{x} / \mathrm{y} / \mathrm{s} /$ es evidenciada sólo una vez. En general, el fonema /r/ fue sustituido con mayor frecuencia por los fonemas /l/, /r/, $/ ð /$ y $/ \mathrm{d} /($ ver Cuadro 4).

Cuadro 4. Sustituciones más frecuentes de la vibrante múltiple

\begin{tabular}{|c|c|c|c|c|}
\hline Tipo de sustitución y porcentaje & & Ejemplos & & Edad/grupo etario \\
\hline$/ \mathrm{r} / \mathrm{-}->[1] 26 \%$ & $\begin{array}{l}\text { ['go.lo] } \\
\text { [le.'lok] } \\
\text { [le.'lox] }\end{array}$ & $\begin{array}{l}\text { /'go.ro/ } \\
\text { /re.'lox/ } \\
\text { /re.'lox/ }\end{array}$ & \begin{tabular}{|l|} 
"gorro" \\
"reloj” \\
"reloj” \\
\end{tabular} & $\begin{array}{l}2 ; 3(\mathrm{I}) \\
3 ; 3 \text { (III) } \\
3 ; 10 \text { (IV) }\end{array}$ \\
\hline$/ \mathrm{r} /-\rightarrow[\mathrm{r}] 23 \%$ & $\begin{array}{l}\text { ['re.ßa.'lo] } \\
\text { ['go.fo] } \\
\text { ['pe.ro] }\end{array}$ & $\begin{array}{l}\text { /'res. } \beta \text { a.'lo/ } \\
\text { /'go.ro/ } \\
\text { /'pe.ro/ }\end{array}$ & $\begin{array}{l}\text { “resbaló” } \\
\text { "gorro" } \\
\text { "perro" }\end{array}$ & $\begin{array}{l}2 ; 5 \text { años (I) } \\
3 ; 0 \text { años (III) } \\
3,6 \text { años (IV) }\end{array}$ \\
\hline$/ \mathrm{r} /$--> [ð] $13 \%$ & $\begin{array}{l}\text { ['go.ðo] } \\
\text { ['pe.ðo] } \\
\text { ['go.ðo] }\end{array}$ & $\begin{array}{l}\text { /'go.ro/ } \\
\text { /'pe.ro/ } \\
\text { /'go.ro/ }\end{array}$ & $\begin{array}{l}\text { "gorro" } \\
\text { "perro" } \\
\text { "gorro" }\end{array}$ & $\begin{array}{l}2 ; 5 \text { años (I) } \\
2 ; 8 \text { años (II) } \\
3 ; 11 \text { ańos (IV) }\end{array}$ \\
\hline$/ \mathrm{r} / \rightarrow[\mathrm{d}] 13 \%$ & $\begin{array}{l}\text { ['de. } \beta \text { a'lo] } \\
\text { ['der.ßa'lo] } \\
\text { ['dwe.ðas] }\end{array}$ & $\begin{array}{l}\text { /res.ßa.'1o/ } \\
\text { /res.ßa.'lo/ } \\
\text { /rwe.ðas/ }\end{array}$ & $\begin{array}{l}\text { “resbaló” } \\
\text { “resbaló” } \\
\text { “ruedas” }\end{array}$ & $\begin{array}{l}2 ; 8 \text { años (II) } \\
\text { 3;1 años (III) } \\
\text { 3;11 (IV) }\end{array}$ \\
\hline
\end{tabular}

En definitiva, la vibrante múltiple fue sustituida con mayor frecuencia por las consonantes líquidas [l] y [r] y por las consonantes dentales [ð] y [d] en todos los grupos etarios (Figura 2). 
Figura 2. Porcentaje de sustitución del fonema /r/ según grupo etario

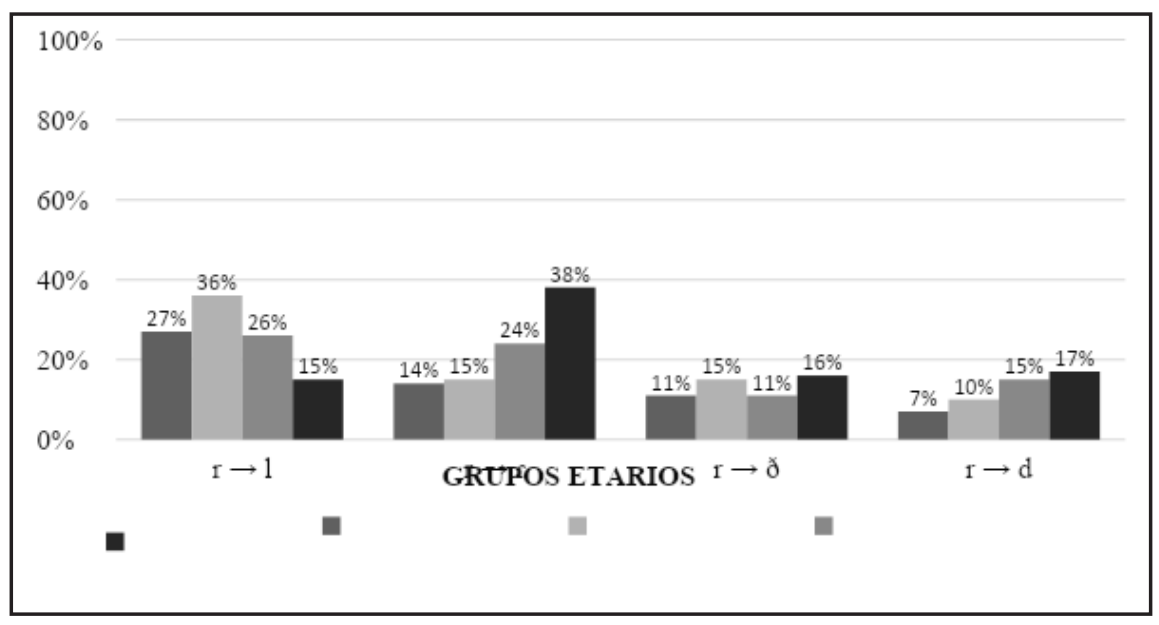

Por otro lado, la vibrante simple en posición aislada fue sustituida por los siguientes fonemas: [b], [d], [ð], [d] $,[\mathrm{f}],[\mathrm{\gamma}],[\mathrm{g}],[\mathrm{j}],[\mathrm{k}],[\mathrm{l}],[\mathrm{m}],[\mathrm{n}],[\mathrm{y}],[\mathrm{p}],[\mathrm{r}],[\mathrm{t}],[\mathrm{w}],[\mathrm{x}],[\mathrm{K}]$ y $[\beta]$. El mayor porcentaje de sustituciones se constataron por las consonantes [l] 28\%, [ð] $28 \%$ y [n] $13 \%$ (ver Cuadro 5).

Cuadro 5. Sustituciones más frecuentes de la vibrante simple

\begin{tabular}{|c|c|c|c|c|}
\hline Tipo de sustitución y porcentaje & & Ejemplos & & Edad/ grupo etario \\
\hline$/ \mathrm{f} / \mathrm{-}^{->}[\mathrm{l}] 28 \%$ & $\begin{array}{l}\text { [na'.la.xa] } \\
\text { [na.'lay.xa] } \\
\text { [xi.'la.fa] }\end{array}$ & $\begin{array}{l}\text { /na.' 'ran.xa/ } \\
\text { /na.'ran.xa/ } \\
\text { /xi.' 'ra.fa/ }\end{array}$ & $\begin{array}{l}\text { "naranja" } \\
\text { "naranja” } \\
\text { "jirafa" }\end{array}$ & $\begin{array}{l}\text { 2;3 años (I) } \\
\text { 3;1 años (III) } \\
\text { 3;1 años (III) }\end{array}$ \\
\hline$/ \mathrm{f} / \mathrm{-}$-> [ð] 28\% & 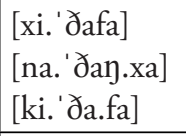 & $\begin{array}{l}\text { /xi.' 'ra.fa/ } \\
\text { /na.' ran.xa/ } \\
\text { /xi.' 'ra.fa/ }\end{array}$ & $\begin{array}{l}\text { “jirafa” } \\
\text { "naranja” } \\
\text { "jirafa" }\end{array}$ & $\begin{array}{l}\text { 2;9 años (II) } \\
\text { 3;1 años (III) } \\
\text { 3;7 años (IV) }\end{array}$ \\
\hline$/ \mathrm{f} /-->[\mathrm{n}] 13 \%$ & $\begin{array}{l}\text { ['xa.na.na. } \\
\text { 'nay.xa] }\end{array}$ & /na'.ranxa/ & "naranja" & 2;8 años (II) \\
\hline
\end{tabular}

En relación a la variable edad, los niños pertenecientes al primer grupo etario recurren más a /l/ y /n/ (22\%) para sustituir la vibrante simple. A fines de los dos ańos de edad el fonema más utilizado es la aproximante /ð/ (29\%), en el tercer grupo es la lateral /1/ (38\%) y a fines de los 3;0 años la /f/ se suele sustituir más veces por la aproximante /ð/ (43\%), nuevamente. El uso del fonema /n/ disminuye con la edad (ver Figura 3). 
Figura 3. Porcentaje de sustitución del fonema /r/ según grupo etario

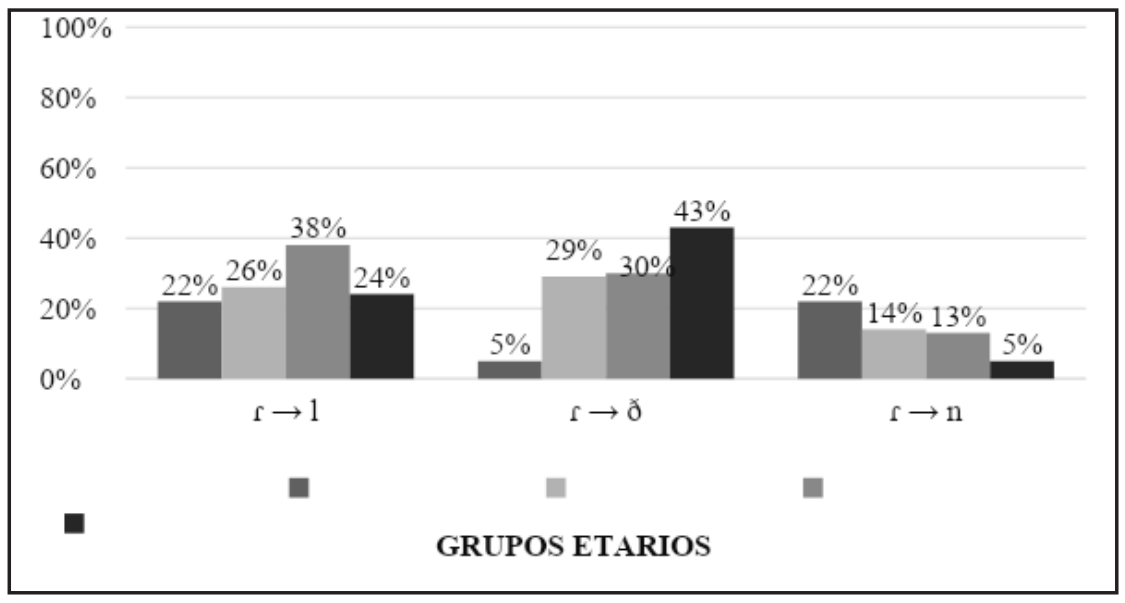

Como se puede observar en el siguiente Cuadro 6, la diferencia promedio en el porcentaje de sustitución de / $/$ / por las consonantes correspondientes a /l/, /ð/ y /n/, es particularmente relevante en el grupo etario 1 (niños de 2,0 a 2,5 ańos) en comparación con el resto de los rangos de edad. Estas diferencias son estadísticamente significativas con un valor-p inferior a 0.05 .

Cuadro 6. Diferencia de medias porcentuales en el \% de sustitución de /f/ por /l/, /ð/ y/n/ según rango etario

\begin{tabular}{|c|c|c|c|}
\hline $\begin{array}{l}\text { \% Sustituciones de /f/ por /1/, } \\
/ \text { / } / \mathbf{y} / \mathbf{n} / \text { según rango etario }\end{array}$ & \multicolumn{3}{|c|}{$\begin{array}{l}\% \text { Sustituciones de } / \varsigma / \text { por } / 1 /, / ð / \mathbf{y} / \mathbf{n} / \\
\text { Diferencia de medias porcentuales }(\mathbf{i}-\mathbf{j})\end{array}$} \\
\hline \multirow{2}{*}{ G1: De 2,0 a 2,5 años (i) } & G2 (j) & G3 (j) & G4 (j) \\
\hline & $-7 \% *$ & $-11 \% *$ & $-8 \% *$ \\
\hline \multirow{2}{*}{ G2: De 2,6 a 2,11 años (i) } & G1 (j) & G3 (j) & G4 (j) \\
\hline & $7 \% *$ & $-4 \%$ & $-1 \%$ \\
\hline \multirow{2}{*}{ G3: De 3,0 a 3,5 años (i) } & G1 (j) & G2 (J) & G4 (j) \\
\hline & $11 \% *$ & $4 \%$ & $3 \%$ \\
\hline \multirow{2}{*}{ G4: De 3,6 a 3,11 años (i) } & G1 (j) & G2 (j) & G3 (j) \\
\hline & $8 \% *$ & $1 \%$ & $-3 \%$ \\
\hline
\end{tabular}

${ }^{*}$ Diferencias de medias significativas con valor-p $<0.05$. Test Anova de un factor 


\subsection{Grupo etario}

En la Figura 4 se observa que la adquisición de las consonantes vibrantes simple y múltiple es gradual. Tanto en el primer como en el segundo grupo etario, se demostró un bajo porcentaje de emisión normal para ambas vibrantes, 1,5 y $7 \%$, respectivamente. En definitiva, se observa que el porcentaje de emisión normal aumenta según el grupo de edad. En el último grupo etario, la vibrante múltiple se emite normalmente un 24,4\%, mientras que, la vibrante simple un 59,7\%. Alrededor de los 4;0 años la emisión de la vibrante simple es cercana al 60\%, datos que coinciden con los de otros estudios (Torres et al. 2016). Lo anterior demuestra que la vibrante múltiple es de lenta adquisición y uno de los fonemas que se adquiere en última instancia (Vivar y León 2009).

Figura 4. Porcentaje de emisión normal del fonema vibrante (simple y múltiple) según grupo etario.

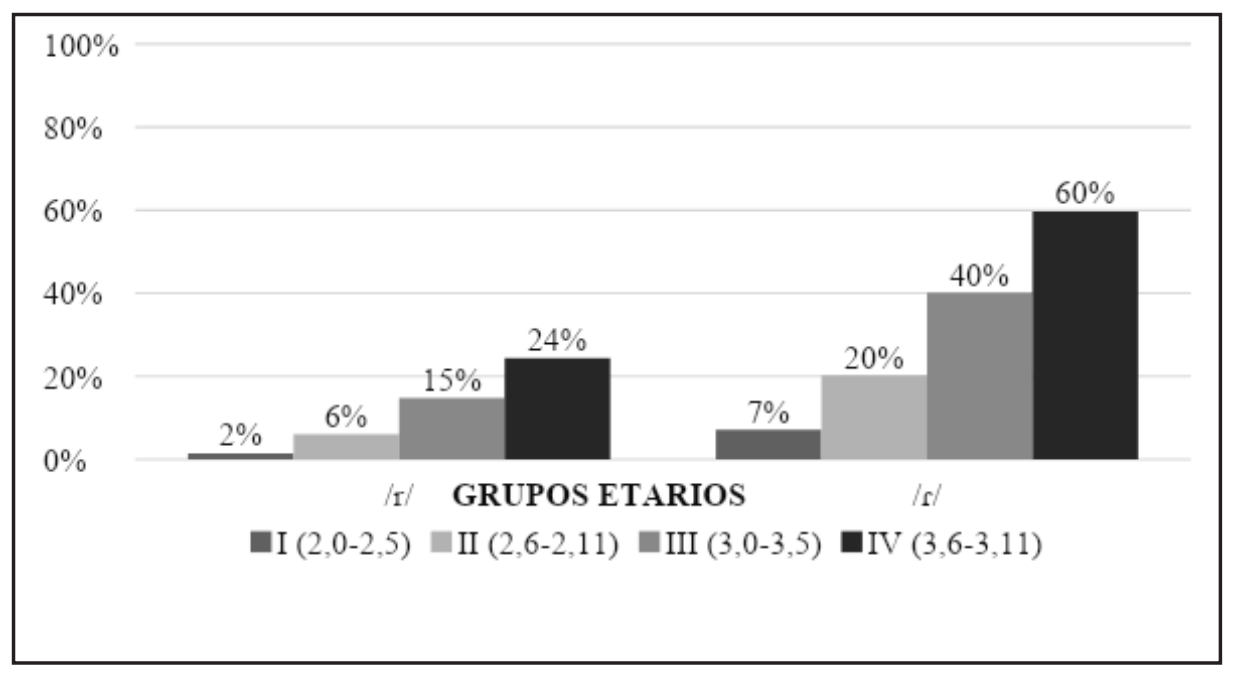

En los cuadros 7.1 y 7.2, se puede observar que el porcentaje de emisión normal del fonema vibrante es significativamente superior en el grupo etario 4, correspondiente a los nińos con edad entre 3,6 a 3,11 años, en comparación con el resto de los grupos etarios considerados en estudio. Estas diferencias en el porcentaje de emisión de son estadísticamente significativas con el valor-p menor a 0.05 . 
Cuadro 7.1. Diferencias de medias porcentuales en el \% de emisión de /r/ según rango etario

\begin{tabular}{|c|c|c|c|}
\hline $\begin{array}{l}\% \text { emisión de } / \mathrm{r} / \text { según } \\
\text { rango etario }\end{array}$ & \multicolumn{3}{|c|}{$\begin{array}{c}\% \text { emisión de } / \mathbf{r} / \\
\text { Diferencia de medias porcentuales }(\mathbf{i}-\mathbf{j})\end{array}$} \\
\hline \multirow{2}{*}{ G1: De 2,0 a 2,5 años (i) } & G2 (j) & G3 (j) & G4 (j) \\
\hline & $-4 \%$ & $-13 \% *$ & $-22 \% *$ \\
\hline \multirow{2}{*}{ G2: De 2,6 a 2,11 años (i) } & G1 (j) & G3 (j) & G4 (j) \\
\hline & $4 \%$ & $-9 \% *$ & $-18 \% *$ \\
\hline \multirow{2}{*}{ G3: De 3,0 a 3,5 años (i) } & G1 (j) & G2 (J) & G4 (j) \\
\hline & $13 \% *$ & $9 \% *$ & $-9 \% *$ \\
\hline \multirow{2}{*}{ G4: De 3,6 a 3,11 años (i) } & G1 (j) & G2 (j) & G3 (j) \\
\hline & $22 \% *$ & $18 \% *$ & $9 \% *$ \\
\hline
\end{tabular}

${ }^{*}$ Diferencias de medias significativas con valor-p $<0.05$. Test Anova de un factor

Cuadro 7.2. Diferencias de medias porcentuales en el \% de emisión de / / / según rango etario

\begin{tabular}{|c|c|c|c|}
\hline $\begin{array}{l}\text { \% emisión de / } / \text { según } \\
\text { rango etario }\end{array}$ & \multicolumn{3}{|c|}{$\begin{array}{c}\text { \% Sustituciones de / } / / \\
\text { Diferencia de medias porcentuales }(i-j)\end{array}$} \\
\hline \multirow{2}{*}{ G1: De 2,0 a 2,5 años (i) } & G2 (j) & G3 (j) & G4 (j) \\
\hline & $-13 \%$ & $-33 \%$ & $-53 \%$ \\
\hline \multirow{2}{*}{ G2: De 2,6 a 2,11 años (i) } & G1 (j) & G3 (j) & G4 (j) \\
\hline & $13 \%$ & $-20 \%$ & $-40 \%$ \\
\hline \multirow{2}{*}{ G3: De 3,0 a 3,5 ańos (i) } & G1 (j) & G2 (J) & G4 (j) \\
\hline & $33 \%$ & $20 \%$ & $-20 \%$ \\
\hline \multirow{2}{*}{ G4: De 3,6 a 3,11 años (i) } & G1 (j) & G2 (j) & G3 (j) \\
\hline & $53 \%$ & $40 \%$ & $20 \%$ \\
\hline
\end{tabular}

${ }^{*}$ Diferencias de medias significativas con valor-p $<0.05$. Test Anova de un factor

En relación al fenómeno de omisión, este fue mayor en el grupo etario I con un $18,2 \%$, mientras que el menor porcentaje de omisión de esta consonante se registró en el IV grupo de edad (7,0\%). En el caso de la vibrante simple, el mayor porcentaje de omisión se evidenció también en el I grupo de edad (38,4\%), mientras que en el IV grupo este porcentaje disminuye a un $7 \%$. La sustitución de $/ \mathrm{r} /$ fue mayormente usada en el III grupo etario (69,9\%), siendo sustituida en el primer grupo tan sólo en un 53,0\%. El fonema / / / fue sustituido más en el II grupo de edad (53,7\%), mientras que el porcentaje disminuye en el grupo etario IV con un 32,6\% (Figura 6). 
De acuerdo a la Figura 5, la producción de la vibrante múltiple aumenta con la edad, mientras que los fenómenos articulatorios de omisión y de sustitución disminuyen. Se observa que, según edad, los porcentajes de emisión normal como de omisión no difieren significativamente, aunque sí se evidencia diferencia en el fenómeno de sustitución con respecto a los anteriores, pues éste comienza a ser utilizado en un 53,0\% (I grupo etario), porcentaje que aumenta con la edad. En el III grupo de edad se evidencia un uso del 69,9\%, el que disminuye en el IV y último grupo etario estudiado, con un 55,2\% (Figura 5).

En la Figura 6 se puede apreciar que la emisión normal de / $/$ inicialmente (grupo de edad I) tiene un desarrollo de 7,1\%, producción que sobrepasa el 50\% en el IV grupo de edad, en otras palabras, al igual que en la emisión de /r/ la producción normal de la vibrante simple también aumenta. En cuanto al fenómeno de omisión, éste disminuye con la edad, ya que en el grupo de edad I tiene un 38,4\% de aparición, mientras que en el IV grupo de edad es de sólo un 7\%. Por último, el fenómeno de sustitución se presenta como el más variable, ya que en el I grupo etario (2;0-2;5 años) su uso es bajo $(37,4 \%)$, uso que aumenta en el II grupo de edad (2;6-2;11 años) con 53,7\% y III grupo etario $(3 ; 0-3 ; 5)$ con $70 \%$, para disminuir en el IV grupo (55\%). Comparando ambas figuras, se puede concluir que la emisión normal de la vibrante simple es mayor que la emisión normal de la vibrante múltiple en todos los grupos etarios estudiados.

Figura 5. Emisión normal, omisión y sustitución del fonema /r/ según grupo etario.

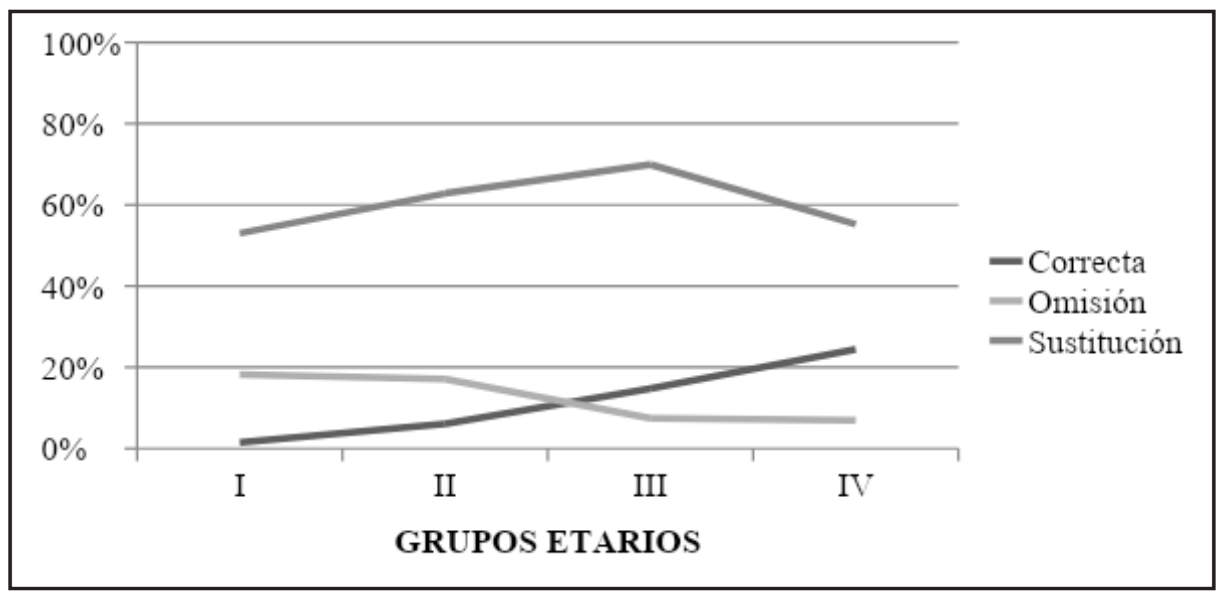


Figura 6. Emisión normal, omisión y sustitución del fonema /r/ según grupo etario

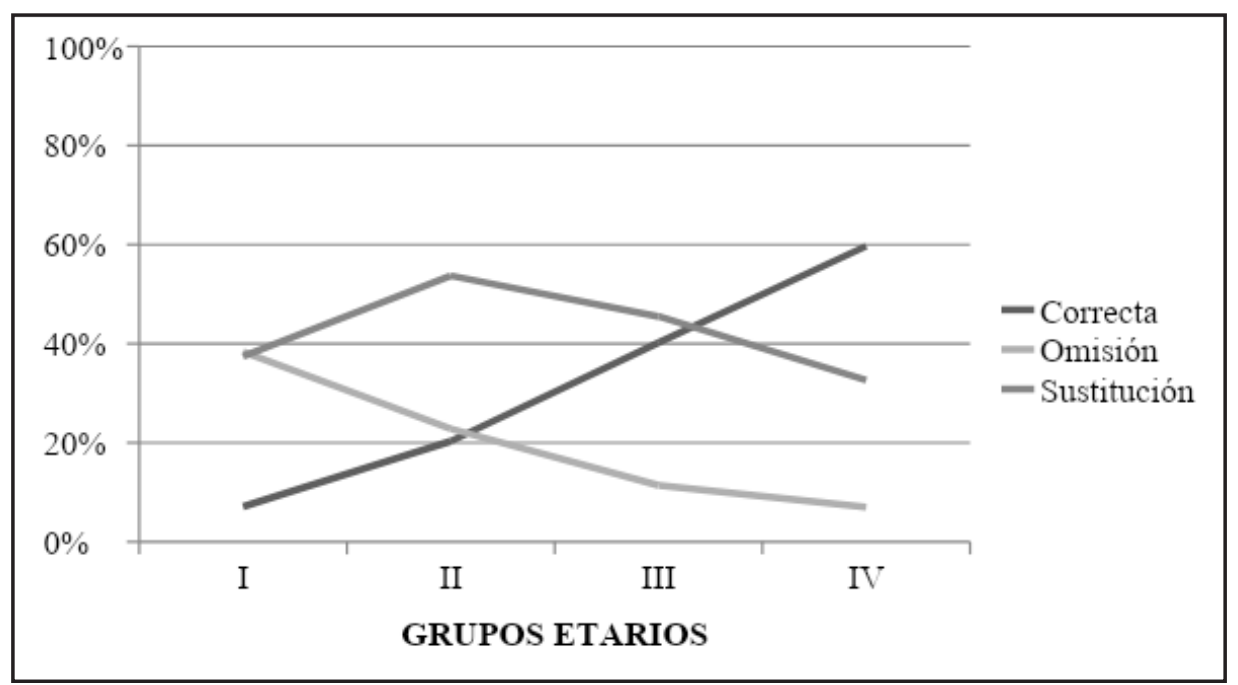

\subsection{Nivel socioeconómico (NSE)}

El porcentaje de emisión normal de los fonemas vibrantes según nivel socioeconómico (alto, medio y bajo) se presenta en la Figura 7. Se evidencia que el NSE alto presenta un menor porcentaje $(8,1 \%)$ de producción de la vibrante múltiple con 14 emisiones normales, en comparación con el NSE medio y bajo, el primero con 39 emisiones $(15,5 \%)$ y el segundo con 27 emisiones normales (12,3\%). El mayor número de emisiones normales de la vibrante simple corresponden al NSE bajo con 63 emisiones (38,2\%), seguido por el NSE alto con 41 emisiones $(31,8 \%)$ y, por último, el NSE medio con 58 emisiones $(30,7 \%)$. Se puede concluir que no existen diferencias sociales y económicas significativas durante la producción de los fonemas vibrantes en esta etapa de la adquisición fonológica, es decir, antes de los cuatro años de edad. 
Figura 7. Porcentaje de emisión normal del fonema vibrante

(simple y múltiple) según nivel socioeconómico

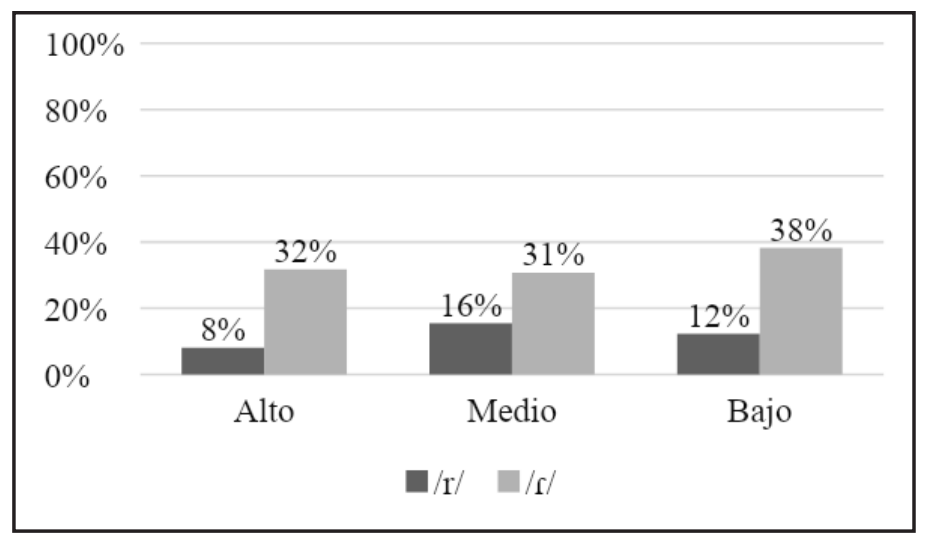

En el cuadro 8 se presenta los resultados obtenidos del análisis de diferencia de medias respecto del porcentaje de emisión normal del fonema vibrante, simple y múltiple, según nivel socioeconómico. Tal como se puede observar, no se evidencia diferencias significativas en la emisión porcentual de este fonema por NSE, dado que el nivel - p es superior a 0,05. De esta manera, como se indicaba anteriormente, el determinante socioeconómico no influye de manera significativa en la producción de fonemas vibrantes en la etapa de adquisición fonológica en niños con una edad inferior a 4 años.

Cuadro 8. Diferencias de medias porcentuales en el \% de emisión normal del fonema vibrante (simple y múltiple) según NSE

\begin{tabular}{|l|c|c|c|}
\hline & NSE (Alto - Medio) & NSE (Alto - Bajo) & NSE (Medio - Bajo) \\
\hline Vibrante simple $(/ \mathrm{r} /)$ & $-8 \%$ & $-4 \%$ & $-4 \%$ \\
\hline Vibrante múltiple $(/ \mathrm{r} /)$ & $1 \%$ & $-6 \%$ & $-7 \%$ \\
\hline
\end{tabular}

*Diferencias de medias significativas con valor-p $<0.05$. Test Anova de un factor

*No se evidencian diferencias de medias significativas con valor-p $<0.05$. Test Anova de un factor

El porcentaje de omisión del fonema /r/ fue mayor en el NSE medio con un 13,5\% y el menor porcentaje de omisión de esta consonante se registró en el NSE bajo (10,5\%). El mayor porcentaje de omisión de la vibrante simple se evidenció en el NSE alto (20,9\%), mientras que en el NSE bajo la omisión fue tan sólo de 16,4\%. Según la Figura 8, el 
mayor porcentaje de sustitución de la vibrante múltiple se registró en el NSE alto (66,3\%), mientras que este porcentaje disminuye en el NSE medio (54,8\%). El mayor porcentaje de sustitución del fonema / $\mathrm{f} /$ se evidenció en el NSE medio $(46,0 \%)$ y el menor en el NSE alto $(39,5 \%)$.

Las Figuras 8 y 9 muestran que la producción normal, la omisión y la sustitución tanto de la vibrante múltiple como de la vibrante simple varían según el NSE. Los niños de la muestra recurren mayormente a la sustitución durante la emisión de los fonemas / $\mathrm{r}$ / $\mathrm{y} / \mathrm{r} /$, independiente del NSE al que pertenezcan. Sin embargo, el porcentaje de sustitución de la vibrante múltiple es mayor en los tres niveles socioeconómicos, en contraste con la sustitución de la vibrante simple. El NSE medio, por ejemplo, sustituye menos la /r/ $(54,8 \%)$ y más la /r/ $(46,0 \%)$ en comparación con los otros NSE (alto y bajo). Asimismo, se aprecia que durante la emisión de la vibrante múltiple no existe diferencia significativa entre los fenómenos omisión y producción normal, ya que sus porcentajes son semejantes. En el caso de la vibrante simple, los niños pertenecientes a los tres niveles, después de recurrir a la sustitución, continúan con la emisión normal del fonema y por último con la omisión. La emisión normal de /r/ fue mayor en el NSE medio, mientras que la emisión normal de / $/$ / fue mayor en el NSE bajo. No existen diferencias significativas en la omisión de las vibrantes según nivel socioeconómico (Figuras 8 y 9).

Figura 8. Emisión normal, omisión y sustitución del fonema /r/ según nivel socioeconómico

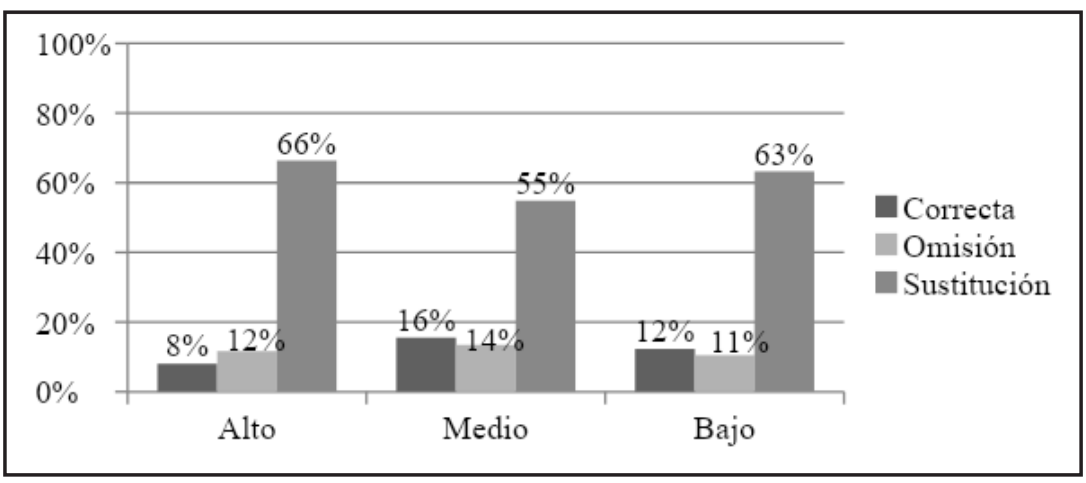


Figura 9. Emisión normal, omisión y sustitución del fonema /r/ según nivel socioeconómico

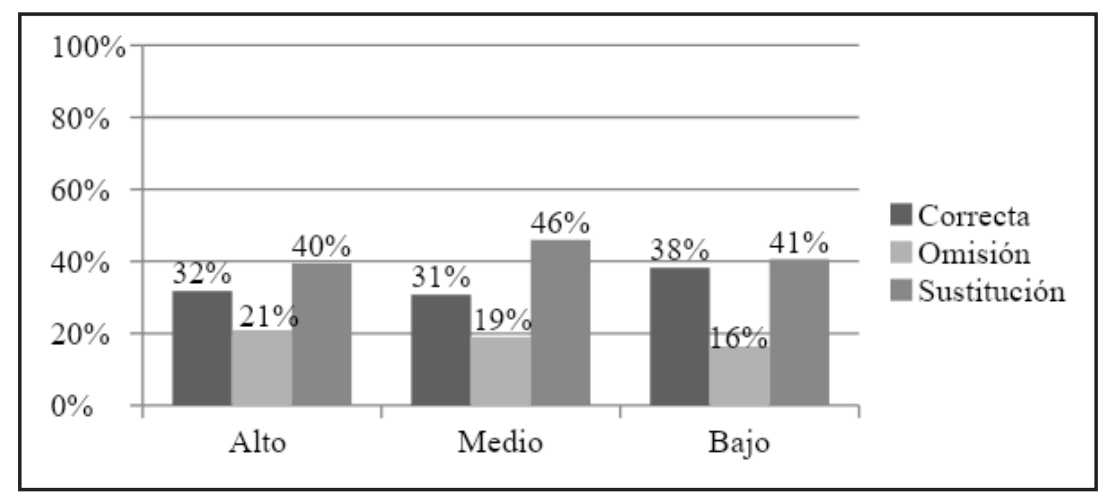

En cuanto al fenómeno de sustitución, los niños de los NSE medio y bajo recurren más a la /l/ para sustituir la vibrante múltiple, aunque la frecuencia y porcentaje es mayor en el NSE bajo con 31\% (Figura 10). Los niños del NSE alto utilizan la lateral como segunda opción, porque usan más la vibrante simple como sustituta de la vibrante múltiple (25\%). Los niños del NSE alto y medio usan la aproximante /ð/ como tercera opción para sustituir la /r/, mientras que los del NSE bajo recurren a la /d/ (Cuadro 9).

Figura 10. Porcentaje de sustitución del fonema /r/ según NSE

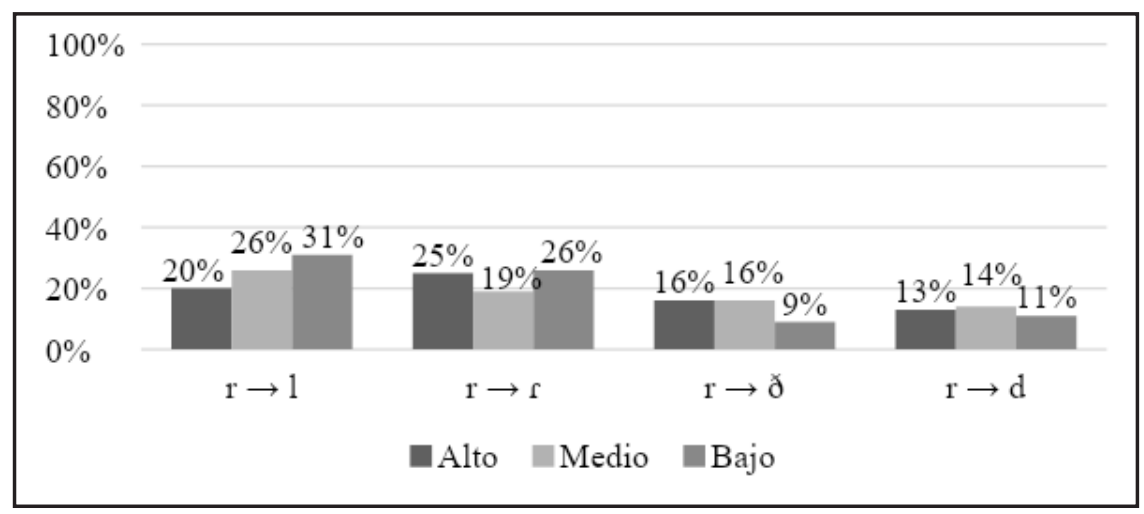


Cuadro 9. Ejemplos de sustitución de /r/ por [l], [r], [ð] y [d] según NSE

\begin{tabular}{|c|c|c|c|c|}
\hline & $\mid \mathbf{r} /$--> [1] & $|\mathbf{r}|-\rightarrow[\mathbf{r}]$ & $\mid \mathbf{r} /$--> [ð] & $\mid \mathbf{r} /-\rightarrow[\mathrm{d}]$ \\
\hline Alto & $\begin{array}{l}\text { ['go.lo] /'go.ro/ } \\
\text { "gorro" } \\
(2 ; 4 \text { años })\end{array}$ & $\begin{array}{l}\text { ['pe.rod] /'pe.ro/ } \\
\text { "perro" } \\
\text { (2;10 años) }\end{array}$ & $\begin{array}{l}\text { ['go.ðo] /'go.ro/ } \\
\text { "gorro" } \\
\text { (2;5 años) }\end{array}$ & $\begin{array}{l}\text { ['de. } \beta \text { a.' 'lo] /res. } \\
\beta \text { a.' lo/ } \\
\text { "resbaló" } \\
(2 ; 8 \text { años })\end{array}$ \\
\hline Medio & $\begin{array}{l}\text { [le.' lox] /re. 'lox/ } \\
\text { "reloj" } \\
\text { (3;10 años) }\end{array}$ & $\begin{array}{l}\text { ['go.ro] /'go.ro/ } \\
\text { "gorro" } \\
\text { (2;9 años) }\end{array}$ & $\begin{array}{l}\text { ['pe.ðo]' /pe.ro/ } \\
\text { "perro" } \\
(2 ; 8 \text { años })\end{array}$ & $\begin{array}{l}\text { [de.' lok] } \\
\text { /re. 'lox/ } \\
\text { "reloj”" } \\
(3 ; 1 \text { años })\end{array}$ \\
\hline Bajo & $\begin{array}{l}\text { [le.' 'lox] /r.e'lox/ } \\
\text { "reloj" (2;5 años) }\end{array}$ & $\begin{array}{l}\text { ['pe.ro] /'pe.ro/ } \\
\text { "perro" } \\
\text { (2;5 años) }\end{array}$ & $\begin{array}{l}\text { ['go.ðo]/'go.ro/ } \\
\text { "gorro" } \\
\text { (2;8 años) }\end{array}$ & $\begin{array}{l}\text { ['der.ßa.' lo] } \\
\text { /res.ßa.'lo/ } \\
\text { "resbaló" (3;1 años) }\end{array}$ \\
\hline
\end{tabular}

En relación con el fenómeno de sustitución de la vibrante simple en función del NSE, se evidenció que los niños pertenecientes a los NSE alto y medio, utilizan más la aproximante /ð/ (41\% y 26\% respectivamente) para sustituir la vibrante simple, mientras que los del NSE bajo recurren a la /l/ (39\%) con el mismo fin. El uso de /n/, en comparación con las otras consonantes, en los tres NSE es menor, aunque el porcentaje es mayor en NSE medio (17\%), debido a que en este nivel la producción de los tres fonemas es semejante (ver Figura 11 y Cuadro 10).

Figura 11. Porcentaje de sustitución del fonema / / / según NSE

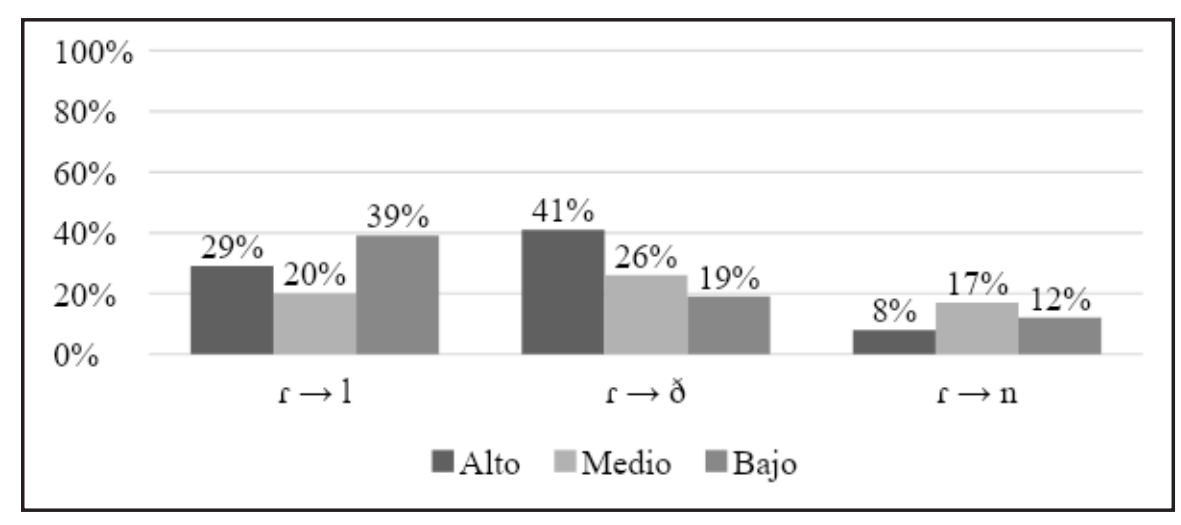


Cuadro 10. Ejemplos de sustitución de /f/ por [l], [ð] y [n] según nivel socioeconómico

\begin{tabular}{|c|c|c|c|}
\hline & $|\mathbf{f}|-->[1]$ & /r/ $/->[ð]$ & $\mid \mathrm{r} / \mathrm{H}^{-->}[\mathrm{n}]$ \\
\hline Alto & $\begin{array}{l}\text { [na.'la.xa] /na.' 'ran.xa/ } \\
\text { "naranja" } \\
\text { (2;3 años) }\end{array}$ & & \\
\hline Medio & $\begin{array}{l}\text { [na.'lay.xa] /na.' ran.xa/ } \\
\text { "naranja" } \\
\text { (3;1 años) }\end{array}$ & $\begin{array}{l}\text { [da'.ðay.ka] /na'.ran.xa/ } \\
\text { "naranja" } \\
\text { (2;8 años) }\end{array}$ & \\
\hline Bajo & $\begin{array}{l}\text { [xi.' la.fa] /xi. 'ra.fa/ } \\
\text { "jirafa” } \\
\text { (3;1 años) }\end{array}$ & $\begin{array}{l}\text { [a.ma.'ði.Кo] /a.ma.' 'i. Кo/ } \\
\text { "amarillo" } \\
\text { (3;0 años) }\end{array}$ & $\begin{array}{l}\text { [da.' nạ.xa] / na' ran.xa/ } \\
\text { "naranja" } \\
\text { (2;5 años) }\end{array}$ \\
\hline
\end{tabular}

\section{DisCuSión Y CONCLUSIONES}

Se investigó la adquisición de las consonantes vibrantes en el español de Chile en una muestra compuesta por 161 informantes, divididos en cuatro grupos etarios, desde los 2;0 a los 3;11 años y los resultados fueron analizados en función de las variables edad y NSE. En términos generales, se evidenció que la adquisición de las consonantes vibrantes es paulatina según avanza el niño en edad (grupos etarios). Lo anterior se observa, por un lado, en los bajos porcentajes de emisión normal de ambas vibrantes en los dos primeros grupos de edad. Alrededor de los 4 años la emisión de la vibrante simple es cercana al $60 \%$, datos que coinciden con los de otros estudios (Hormazábal et al. 2013 y Torres et al. 2016), en contraste, el porcentaje de adquisición de la vibrante múltiple sólo es de un tercio (Hormazábal et al. 2013 y Torres et al. 2016).

En cuanto al fenómeno de sustitución las vibrantes múltiples fueron sustituidas con mayor frecuencia por las consonantes líquidas $[1]$ y $[\mathrm{r}]$ y por las consonantes dentales [ð] y [d]; mientras, las vibrantes simples por las consonantes [1], [ð] y [n]. Los resultados anteriores coinciden con los encontrados por Bosch (2004) quien señala que a los 3 años un $48 \%$ lateraliza las vibrantes y un $66 \%$ sustituye la vibrante múltiple (reemplazo por [r] o [ð]), mientras que un $14 \%$ de los niños a los 3;0 ańos sustituye la vibrante simple por [ð]. Los procesos de sustitución son característicos y frecuentes en el lenguaje infantil siendo descritos ya por Jakobson en 1941. Describir y sistematizar la aparición de las sustituciones en los segmentos permite conocer las rutas fonológicas que siguen los nińos para llegar a la forma adulta, ya que no es habitual que de manera inmediata los menores produzcan los sonidos según la norma adulta. En definitiva, durante la adquisición fonológica, independiente de la lengua, se evidencia la presencia de múltiples procesos fonológico-fonéticos: elisiones, sustituciones, epéntesis, reducciones, modificaciones fonéticas, etc., y una aproximación gradual y constante hacia el modelo fonológico adulto (Lleó, 1997; Ingram, 1983; Vivar, 2009; Bosch, 2004). En este sentido, los niños/as construyen su sistema fonológico a medida 
que lo van usando, por lo que es necesario observar y describir, durante las primeras etapas, los mecanismos propios de tal proceso y considerarlos como rasgos con relevancia evolutiva (Fernández 2007).

En relación con el nivel socioeconómico, se evidenció que en la muestra analizada no existen diferencias significativas en el desempeńo normal de las consonantes vibrantes. Estos datos no coinciden con los evidenciados por Pávez et al. (2009) y Pandolfi \& Herrera (1990) quienes investigaron la adquisición fonológica infantil desde la perspectiva de los procesos fonológicos de simplificación.

Finalmente como proyecciones, consideramos que es necesario realizar un estudio articulatorio estadísticamente significativo que permita establecer las edades de adquisición de los fonemas en espańol de Chile. Lo anterior, no implica obviar las diferencias individuales, sino entregar un panorama lingüístico normativo que apoye las evaluaciones que realizan los profesionales del lenguaje infantil.

Por otro lado, como ya se había señalado en líneas anteriores, en la investigaciones sobre adquisición fonológica existen algunos segmentos que resultan más complejos de analizar que otros, debido a la variación que presentan dentro de una comunidad. Específicamente en Chile, los estudios de variación de segmentos son escasos (Miller 2013, Vivar, en prensa), sin embargo, es importante investigar sobre este tópico en fonología para conocer relación entre el desarrollo fonológico y la adquisición de la variación.

\section{OBRAS CitADAS}

Aceña, José María. 1996. Adquisición y desarrollo del nivel fonológico: intervención didáctica en retrasos y trastornos fonológicos y fonéticos. Dúlcidica 8: 11-27.

Anderson, Raquel y Bruce, L. Smith. 1987. Phonological development of two-years-old monolingual Puerto Rican Spanish-speaking children. Journal of Child Language 14: 57-78.

Ávila, R. 1990. Cuestionario para la Evaluación de la Fonología Infantil. Psicolingüistica: Adquisición y Desarrollo de L1 y L2 y Fonética y Fonología. México: El Colegio de México. Berko Jean y Nan Bernstein. 2010. Desarrollo del lenguaje. Madrid: Ed Pearson.

Bosch, Laura. 2004. Evaluación fonológica del habla infantil. España: Elsevier Masson.

Borland, Karen. 2004. La variación y distribución alofónica en el habla culta de Santiago de Chile. ONOMÁZEIN 10, 2: 103-115.

Camargo, Maryluz. 2006. Desarrollo fonético-fonológico del español en niños. Umbral Cientifico 9: 5-9.

Coloma, Carmen; Pavez, María; Maggiolo, Mariangela y Peñaloza, Christian. 2010. Desarrollo fonológico en niños de 3 y 4 años según la fonología natural: Incidencia de la edad y del género. Signos 43, 72: 31-48.

Dinnsen, Daniel; Chin, Steven; Elbert, Mary y Powell, Thomas. 1990. Some constraints on functionally disordered phonologies: Phonetic inventories and phonotactics. Journal 
of Speech Language and Hearing Research 33, 1: 28-37.

Fernández, Milagros. 2007. La actualidad de los estudios sobre lenguaje infantil. Lynx: Panorámica de estudios lingüísticos 6: 3-40.

Flores, Ana y Esthela Ramírez. 2016. Teoría universalista de Jakobson y orden de adquisición de los fonemas consonánticos de español mexicano: estudio de caso. ONOMÁZEIN 34:1-7.

Garayzábal-Heinze, Elena. 2006. Adquisición del lenguaje y pruebas de evaluación fonológica: una revisión desde la Lingüística. ReVEL 4, 7: 1-23.

Garnica, Olga y Edwards, Mary. 1977 Phonological variation in children's speech: the trade-off phenomenon. Working Papers y Linguistics 22: 81-87.

Goldstein, Brian y Patricia Cintrón. 2000. An investigation of phonological skills in Puerto Rican Spanish-speaking 2 years-old. Clinical Linguistics \& Phonetics 15, 5: 343-361.

González Valenzuela, María José. 1989. Análisis del desarrollo fonológico en sujetos malagueños. Infancia y aprendizaje 12, 48: 7-24.

Hormazábal, Katerine; Larrea, Rosario; Muñoz, Monserrat; Ruz, Melanie y Paula Toro. 2013. Edad de adquisición de fonemas líquidos en un grupo de niños chilenos de entre 3 y 4 ańos 11 meses de nivel socioeconómico medio en la Región Metropolitana (Seminario de Licenciatura en Fonoaudiología). Santiago, Chile: Universidad de Chile.

Ingram, David.1983. Phonological disability in children. London: Edward Arnold.

Jakobson, R. 1941/1968. Kindersprache, Aphasie und allgemeine Lautgesetze/Child language, aphasia and phonological universals. Berlín: Suhrkamp.

Lleó, Conxita. 1997. La adquisición de la fonología de la primera lengua y de las lenguas extranjeras. Madrid: Visor.

Levelt, Clara Schiller, Niels y Willem, Levelt. 1999/2000. The Acquisition of Syllable Types. Language Acquisition 8: 237-264.

Martínez, Eugenio. 2003. El sonido en la comunicación humana: introducción a la fonética. Barcelona: Edición Octaedro.

Melgar de González, María. 1976. Cómo detectar al niño con problemas del habla. México: Trillas.

Miller, Karen. 2013 Acquisition of variable rules: /s/-lenition in the speech of Chilean Spanish-speaking children y their caregivers. Language, Variation y Change 25: 311-340.

Miras Martínez, Francisco. 1991. El desarrollo fonoarticulatorio del habla infantil. Un estudio descriptivo en niños almerienses de uno a cinco años. Tesis doctoral. Murcia: Universidad de Murcia.

Morales-Front, Alfonso. 2006. Acquisition of syllable structure in Spanish. En MartínezGil \& Colina, eds., Optimality- Theoretic Studies in Spanish Phonology. Amsterdam/ Philadephia: John Benjamins Publishing Company. 497-524.

Navarro Tomás, Tomás. 1918. Manual de pronunciación española. Madrid: Gredos.

Obediente, Enrique. 2007. Fonética y fonología. Mérida, Venezuela: Consejo de Publicaciones Universidad de Los Andes. 
Olmsted, David. 1971. Out of the mouth of babes. The Hague: Mouton.

Oropeza, Minerva. 2017. Adquisición de las consonantes líquidas en el español de México. CPU-e Revista de Investigación Educativa 25: 168-196.

Pandolfi, Ana María y Herrera, María Olivia. 1990. Producción fonológica diastrático de niños menores de tres años. Revista de Lingüística Aplicada 28: 101-122.

Pávez, María Mercedes; Maggiolo, Mariangela; Peñaloza, Christian y Carmen Julia, Coloma. 2009. Desarrollo fonológico en niños de 3 a 6 años: incidencia de la edad, el género y el nivel socioeconómico. Revista de Lingüistica Teórica y Aplicada 47, 2: 89-109.

Quilis, Antonio y Joseph Fernández. 1971. Curso de fonética y fonología españolas. Madrid: CSIC.

Serra i Raventós, Miquel. 1984. Normas estadísticas de articulación para la población escolar de 3 a 7 ańos del área metropolitana de Barcelona. Revista de Logopedia, Foniatría y Audiología 3, 4: 232-235.

Retamal, Nicolás y Soto, Jaime. 2017. Caracterización fonético-auditiva y fonético acústica del fonema vibrante múltiple / $\mathrm{r}$ / en profesionales de 8 ciudades de Chile en situación de lectura en voz alta. Boletín de Filología 52, 1: 245-271.

Sander, Eric. 1961. When are speech sounds learned?. JSHD 37: 55-63.

Soto-Barba, Jaime. 2011. Variación consonántica en el habla urbana y rural de la provincia de Nuble. RLA 49, 2: 111-127.

Stampe, David. 1969. The acquisition of phonetic representation. PCLS, $5^{\text {th }}$ Regional Meeting. 443-454.

Sadowsky, Scott y Gastón Salamanca. 2011. El inventario del español de Chile: Principios orientadores, inventario provisorio de consonantes y sistema de representación (AFICL). ONOMÁZEIN 24, 2: 61-84.

Stokes, Stephanie. y Surendran, Dinoj. 2005. Articulatory Complexity, Ambient Frequency, and Functional Load as Predictors of Consonant Development, Children Journal of Speech, Language, and Hearing Research, Vol. 48: 577-591Templin, Mildred. 1957. Certain language skills in children: their development and interrelationships. Minneapolis: The University of Minnesota Press.

Torres, Felipe; Pino Josué; Peñaloza Christian; Rojas Daniela; Fernández María Angélica; Castro Patricia; Bustos, Mario y Katerine Hormazábal. 2016. Comparación de criterios para determinar la edad de adquisición de fonemas lateral y róticos. Revista Chilena de Fonoaudiología 15: 1-16.

Villegas, Francisco. 2004. Manual de Logopedia. Evaluación e intervención de las dificultades fonológicas. Madrid: Pirámide.

Vivar, Pilar. 2007. Desarrollo fonológico-fonético infantil en un grupo de niños entre 3 y 5, 11 años. Un estudio transversal - descriptivo con aplicación de la prueba articulatoria CEFI (Tesis de magíster). Concepción: Universidad de Concepción.

Vivar, Pilar y Hernán León. 2009. Desarrollo fonológico-fonético en un grupo de niños entre 3 y 5, 11 ańos. CEFAC 11, 2: 190-198. 
ESTUDIOS FILOLÓGICOS

Vivar, Pilar. 2009. Evaluación de grupos consonánticos de ataque complejo en un grupo de niños de la ciudad de Concepción con prueba articulatoria CEFI. ONOMÁZEIN 20: 33-44.

Vivar, Pilar. (en prensa). Producción del fonema /s/ en una muestra de niños hablantes del español de Chile: adquisición de los aspectos dialectales. Revista Lexis. 